\title{
Synchrony in Leafing, Flowering, and Fruiting Phenology of Senegalia senegal within Lake Baringo Woodland, Kenya: Implication for Conservation and Tree Improvement
}

\author{
Stephen F. Omondi, ${ }^{1,2}$ David W. Odee, ${ }^{1}$ George O. Ongamo, ${ }^{2}$ \\ James I. Kanya, ${ }^{2}$ and Damase P. Khasa ${ }^{3}$ \\ ${ }^{1}$ Kenya Forestry Research Institute, P.O. Box 20412, Nairobi 00200, Kenya \\ ${ }^{2}$ School of Biological Sciences, University of Nairobi, P.O. Box 30197, Nairobi 00100, Kenya \\ ${ }^{3}$ Centre for Forest Research and Institute for Systems and Integrative Biology, Laval University, Sainte-Foy, QC, Canada G1V 0A6 \\ Correspondence should be addressed to Stephen F. Omondi; stephenf.omondi@gmail.com
}

Received 18 March 2016; Accepted 19 April 2016

Academic Editor: Kihachiro Kikuzawa

Copyright ( $) 2016$ Stephen F. Omondi et al. This is an open access article distributed under the Creative Commons Attribution License, which permits unrestricted use, distribution, and reproduction in any medium, provided the original work is properly cited.

Leafing, flowering, and fruiting patterns of Senegalia senegal were studied over a period of 24 months from January 2014 to December 2015. The phenological events of the species are bimodal and follow the rainfall patterns. The leafing phase starts during the onset of rains and lasts for 18 weeks. New leaves continued to appear on the new shoots while old leaves persisted to the leaf fall period. Flowering event takes 12 weeks and is concentrated in the months of high relative humidity (April and October) with one-month peak flowering period. Fruiting phase starts at the peak of the rainy seasons (May and November) and peaks in June and December. This phase lasted for 14 weeks. The fruits mature towards the end of the rainy season (January/February and July/August). The fruits open for dispersal mainly in February/March and September during the peak dry season. High synchrony index (SI) was found in leafing (SI: 0.87), flowering (SI: 0.75), and fruiting (SI: 0.85) events among the populations. Temperature, precipitation, and soil moisture content were significantly correlated with the phenological events. Significant variations in floral morphology and fruits traits were also evident. Seed collections should be undertaken in the months of January/February and July/August.

\section{Introduction}

Phenology is often an overlooked aspect of plant ecology, from the scale of individual species to whole ecosystems [1]. However, phenological studies provide knowledge about the patterns of plant growth and development as well as the effects of the environment and selective pressures on flowering and fruiting behavior [2]. Additionally, flowering of certain plants signals agronomic time and changing phenological patterns may also indicate climate change [3]. Detailed investigations of these events can improve understanding of the strong effects of anthropogenic and environmental factors on life-forms in nature and hence be able to facilitate conservation efforts. Temperature and photoperiods, which are reliable signals of seasons, are probably among the best studied environmental factors [4]. Accurate detection of such environmental cues by plants and the resulting plastic response would enable reproduction to occur when climatic conditions are most suitable. Thus, resources and conditions impose bottom-up selective forces on phenology [3]. In simple terms, for plant reproduction, timing is everything [5]. An individual plant that flowers too early, before it has had time to accumulate sufficient material resources, will have a limited capacity for seed production [2]. Conversely, one that delays flowering might gain higher capacity but might also run out of time to use it before the end of the season.

As emphasized by Okullo et al. [6], biologists have begun examining how phenological patterns are influencing reproductive successes of tree species. The flowering phenology of individual trees (duration of flowering as well as 
the pattern of flowering intensity) varies continuously between extremes [5]. At one extreme are species with individual trees producing large numbers of new flowers each day over a short period (a week or less), while species with flowering-individuals in the population that produce small numbers of new flowers almost daily for many weeks are at the opposite extreme [7]. Understanding such occurrences is useful in planning improvement programmes and conservation strategies. The need for recognizing and accounting for phenological development in plants in relation to ecological studies has been reported by Abu-Asab et al. [8]. These studies provide information on functional rhythms of plants and plant communities, where the timing of various phenological events may reflect biotic and/or abiotic environmental conditions. These studies are also important from the point of view of the conservation of tree genetic resources and forestry management as well as for a better understanding of plant species and community level interactions. While few studies have focused on African dryland tree species, studies undertaken so far indicate that, in the tropical savanna, some species produce leaves and flowers before the onset of the wet season while others do so after the onset of the season [9-11]. Although such information is limited, knowledge of how these events happen is very important in tree production management strategies and more so for keystone species such as $S$. senegal.

Senegalia senegal begins its reproductive phenology at relatively young age, mostly at the age of three years at ideal environment [12]. The event, however, varies between populations but these have been reported to occur soon after or just before the rains [11]. Although the phenological data are scarce, the flowering pattern in East Africa is quit variable due to the bimodal rainfall patterns [12]. In some parts of Kenya, the flowering has been observed to occur shortly after the rains and leaf flush but no detailed study has been undertaken to document these events [13]. This includes Lake Baringo ecosystem where commercial exploitation and farmland adoption of the species is viable. Such information is important in conservation and sustainable management of the species [6].

Throughout its distribution in Kenya, S. senegal population has undergone various levels of anthropogenic disturbances and habitat fragmentations more so within Lake Baringo ecosystem [14]. These disturbances have modified the plant communities therein and put pressure on natural regeneration and evolutionary potential of the species [15]. These include the biological processes such as mating systems (pollination and fruit setting) and gene flow. Such disturbed populations will therefore require conservation and management practices that promote sustainable utilization [16]. Execution of viable local conservation strategies based on reproductive processes for $S$. senegal within the ecosystem is therefore required before the species ecological integrity is lost. This is basically because the success of the species will largely depend on its ability to achieve both its vegetative and its reproductive growths. The aim of the present study was to investigate phenological events in S. senegal within Lake Baringo woodland ecosystem in relation to environmental cues at the individual and population levels. This involved
(1) investigation, interpretation, and documentation of the phenoevents; (2) determining the timing of the phenoevents; (3) establishing the relationship between the phenoevents of the species with climatic variables.

\section{Materials and Methods}

2.1. Study Site. Lake Baringo woodland ecosystem is found between $035^{\circ} 35^{\prime} \mathrm{E}, 00^{\circ} 16^{\prime} \mathrm{N}$ and $036^{\circ} 00^{\prime} \mathrm{E}, 00^{\circ} 42^{\prime} \mathrm{N}$. Within the woodland, four S. senegal populations, namely, Kimalel, Kampi Ya Samaki, Lake Bogoria, and Tangulbei, were selected for this study (Figure 1). The ecosystem is characterized by many small hills but majorly step faulted rift valley floor with significant soil type variations [17]. The Tangulbei site exhibits recent volcanic soils while the areas around Kampi Ya Samaki, Kimalel, and Bogoria have deep red soils with high fertility. Some areas show poorly drained with moderately deep to deep clay soils. The temperatures are fairly hot to warm with the mean annual temperatures ranging between 22 and $24^{\circ} \mathrm{C}$. The mean minimum and maximum temperature range from 16 to $18^{\circ} \mathrm{C}$ and 28 to $30^{\circ} \mathrm{C}$, respectively. The ecosystem falls under semiarid ecological zone with mean annual rainfall ranging between 450 and $900 \mathrm{~mm}$ and mean annual potential evapotranspiration ranging between 1650 and $2300 \mathrm{~mm}$. The vegetation within the ecosystem is majorly bushland and Acacia woodland [17].

2.2. Study Species. Senegalia senegal (L.) Willd. (syn. Acacia senegal) is an indigenous African Acacia species that plays an important role in the dryland economy [18]. The species grows up to $15 \mathrm{~m}$ tall and is valued mainly for gum arabic production. Senegalia senegal also play significant role in agricultural production through enhancement of soil fertility and environmental amelioration [12]. The species is also important to the local communities during the dry season as a source of fodder for livestock [19]. Gum arabic is produced by the species through response to injuries caused by animals or incisions by gum collectors. The gum is traded locally and internationally for use in the pharmaceutical, beverage, ink, and lithographic industries as stabilizer and encapsulation agent $[18,20]$. Senegalia senegal is widely spread in tropical and subtropical Africa, from South Africa northwards to Sudan [18]. In Kenya, the species grows in the coastal region to the northern parts through rift valley, in dry AcaciaCommiphora bushlands [21]. However, commercial exploitation is majorly in the northern and rift valley populations [20]. High densities and sometimes pure stands of this species have been observed in some parts of Turkana and Baringo counties $[20,22]$.

2.3. Study Design and Recording of Phenological Events. To document the phenological diversity and synchrony/asynchrony within the woodland, $100 \mathrm{~m} \times 100 \mathrm{~m}$ temporary plots were established at Kimalel, Kampi Ya Samaki, Lake Bogoria, and Tangulbei populations. These populations represent the wider species distribution range within the woodland. Documentation was conducted in two consecutive years (24 months, January 2014 to end of January 2016). Thirty reproductively mature individual trees $(>5 \mathrm{~cm}$ girth and having 


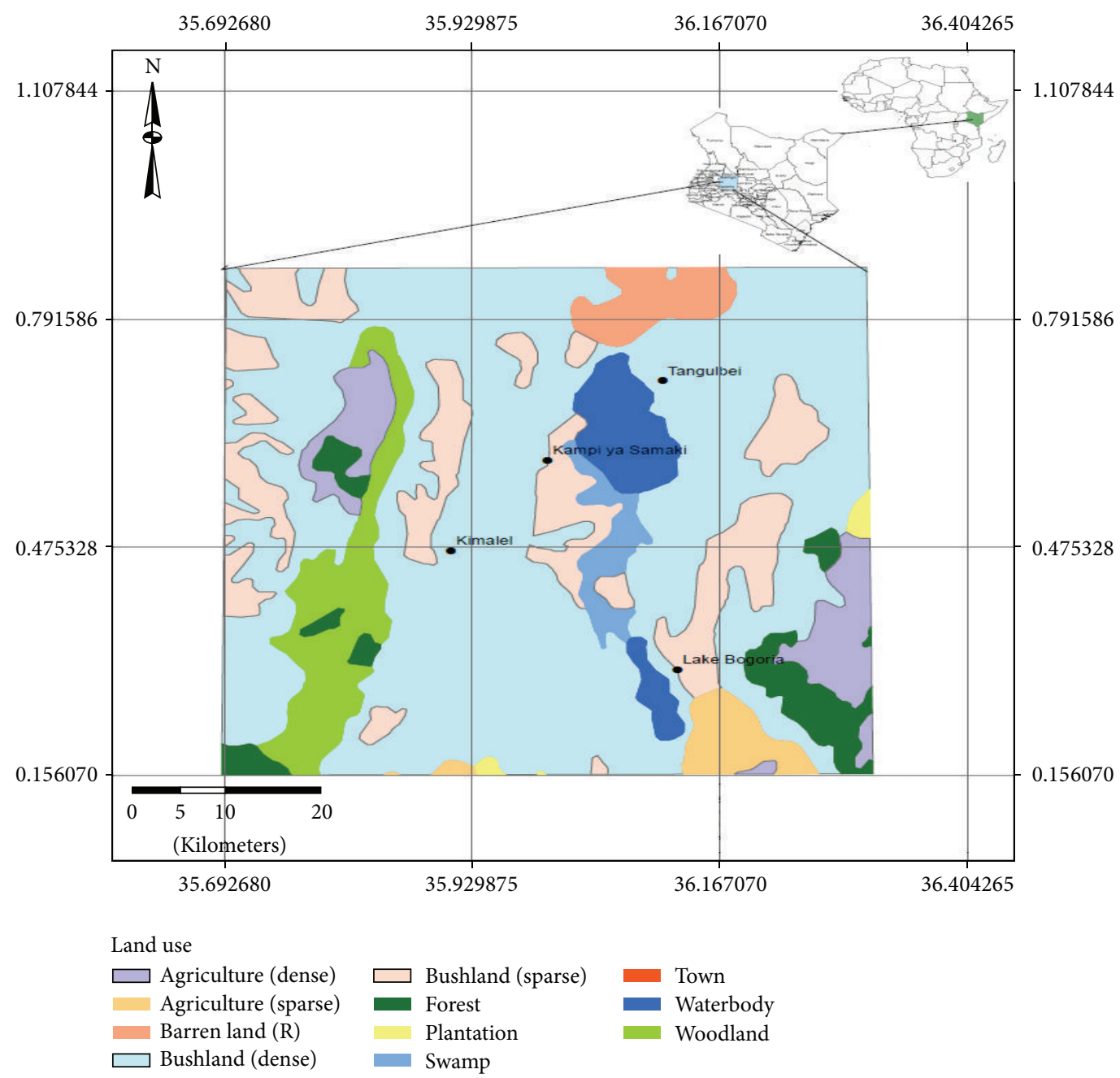

FIGURE 1: Map of Lake Baringo forest ecosystem showing study sites and land use patterns.

a sign of previous-year seed production) per population were selected for the study. Four branches (the branches were distributed in the northern, western, southern, and eastern sides of the tree) per tree were marked and assessed at fortnight intervals. The branches were assessed on onemetre length from the tip. During the assessment, leafing, flowering, and fruiting processes were scored visually. Leaf flush initiation, leaf flush completion, leaf fall initiation, leaf fall completion, leafless period, initiation of flowering, completion of flowering, time lag between start of vegetative (first-leaf flush) and reproductive phases (first-visible flower), initiation of fruiting, completion of fruiting, fruit-fall initiation, and completion of fruit fall were determined. For each of the 120 individual trees monitored, a separate phenological record was maintained. The starting date of a phenophase was assigned to the monitoring date when structures on one or more branches were observed to have entered that phase. The end for the phenophase was assigned to the monitoring date when no branch was observed carrying structure in the phase. At the population level, for each monitoring year, peak flowering and fruiting were used to refer to the months in which the number of individuals observed in that phenophase reached a maximum. During the same period rainfall, soil moisture content, temperature, and relative humidity data were collected. The data were then summarized into monthly values.

2.4. Floral Morphology. Study of the floral morphology followed the protocol described by Nghiem et al. [23] with some modifications. The flowering peak season was chosen and reproductively mature trees used during the phenology study were sampled for this study. During this season, 30 flower inflorescences per tree were collected at anthesis. The flowers were fixed in methanol: acetic acid solution $(3: 1)$ for 4 hours and then the solution was replaced by $70 \%$ ethanol for transportation to the laboratory. In the laboratory, length of each flower inflorescence was measured $(\mathrm{mm})$. The number of flowers per inflorescence was counted and each flower was observed under binocular dissecting microscope to score for presence or absence of a fully developed pistil. The flower and style lengths were measured for all the flowers. 
Another 30 flowers per tree were softened and cleared in a sodium hydroxide solution $(0.8 \mathrm{~N} \mathrm{NaOH})$ for 10 minutes in an oven held at $60^{\circ} \mathrm{C}$ and stained in aniline blue for 30 minutes in readiness for dissection. The style and ovary were separated and the ovary was divided into two halves. Following the procedures described by Martin [24], each ovary was placed in a drop of glycerol and viewed by fluorescence microscope under UV light and the number of ovules was counted. The diameters of 30 stigmas and 30 polyads per inflorescence were also determined using light microscopy. The images were then digitally captured and stigma and polyad dimensions were measured using Axiovision 3.1 software. Pollen from 30 inflorescences was collected from the same 30 trees per population and dried in desiccators containing silica gel for 3 hours and then sieved through a stainless steel sieve of $63 \mathrm{~mm}$ aperture mesh. Pollen was then placed onto a growth medium of $1 \%$ agar, $20 \%$ sucrose, and $0.01 \%$ boric acid at $26^{\circ} \mathrm{C}$ for determination of polyad germination and number of pollen tubes per polyad. Germination percentages were recorded by examining three replicates of $\sim 300$ polyads per tree by light microscope after 4-hour incubation. A polyad was scored as having germinated when the length of at least one pollen tube was longer than the polyad diameter.

Thirty pods were collected from the 30 trees per population when brown and beginning to dehisce. Each pod was put in a separate plastic sampling bag and the seeds were extracted inside the bag. The pods were measured for length and width. All seeds within the pod were examined and classed either as undeveloped with an empty or wrinkled appearance or as fully developed with a normal filled appearance. The number of undeveloped and developed seeds per pod was recorded. Length and width of the developed seeds were measured using electronic caliper. The seed samples were also weighed to calculate mean seed weight for each combination.

2.5. Data Analyses. Phenology events of the populations were summarized by recording occasions separately and for the four populations combined. Various intra- and interpopulation synchrony indices including leaf development, flower formation, and fruit developments were determined as described by Devineau [25]. Synchrony index was determined as the ratio between the mean individual duration of a phenological phase and the overall duration of the phase. The totals of the different individuals of each population for leafing, flowering, and fruiting were calculated for each month. The ratio of the number of phenological observations to the total number of observed trees provided percentages in each stage. Spearman's rank correlation was used to establish any correlation between phenological events with total monthly rainfall, mean maximum and minimum air temperature, soil water content, and mean relative humidity. Univariate analysis of the inflorescence, flower, pods, and seed parameters was performed. One-way analyses of variance were used to test differences among the populations and their significance was tested through Fisher's least significance difference (LSD). All data were analyzed using GenStat 16th edition software.

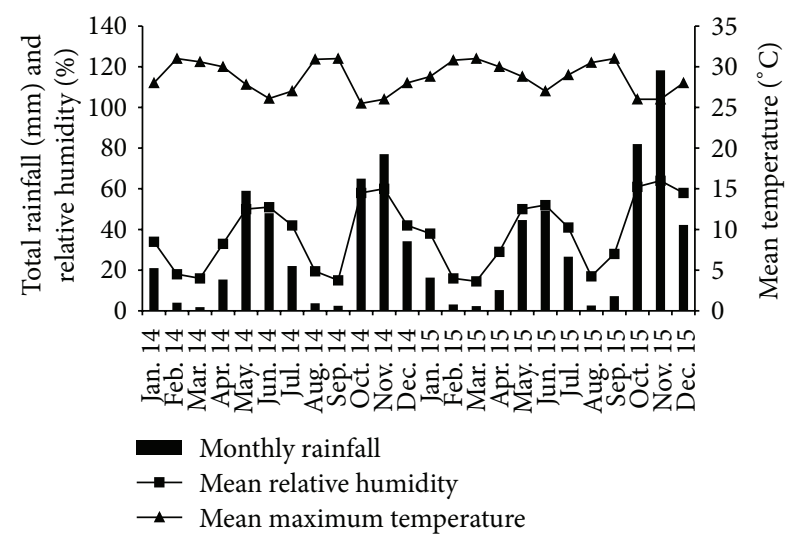

FIGURE 2: Variation in total monthly rainfall, mean maximum temperature, and mean soil moisture content.

\section{Results}

3.1. Environmental Cues. During the two years of study, significant variation in monthly precipitation was reported ranging from $2.3 \mathrm{~mm}$ to $118 \mathrm{~mm}$, although no significant difference was recorded among the populations. The rainfall distribution mainly followed the typical bimodal pattern with the months with higher precipitation being May/June and October/November (Figure 2). Overall, the annual total rainfall differed between the two years with the year 2015 recording more rainfall amounts $(650 \mathrm{~mm})$ than the year 2014 $(582 \mathrm{~mm})$. The mean temperatures varied significantly and followed the rainfall patterns with the rainy months recording lower temperatures than months with no rains. Mean daily maximum temperatures ranged between $26^{\circ} \mathrm{C}$ and $31^{\circ} \mathrm{C}$ and the monthly distributions are as shown in Figure 2. The mean monthly minimum temperatures are relatively constant and falling between $15^{\circ} \mathrm{C}$ and $20^{\circ} \mathrm{C}$. Mean daily relative humidity for each month ranged from 14.5 to $67 \%$. It was observed that the higher the monthly rainfall, the higher the mean relative humidity and the lower the mean maximum atmospheric temperatures (Figure 2). The soil moisture content was high during the rainy months and low during the dry months. These trends were similar during the two years of the study.

Records of leafing, flowering, and fruiting for the twoyear study were made for 120 trees (30 each for Tangulbei, Kampi Ya Samaki, Kimalel, and Lake Bogoria). In general, all the phenological phases were periodic and followed the weather patterns. Due to the two rainy seasons in each year, occurrences of two growth seasons per year are reported (Figure 3 and Table 2).

3.2. Leafing Phenology. Within Lake Baringo woodland, leaf initiation in S. senegal started with the emergence of leaf buds during the onset of precipitation. This occurred between the last week of September and the first week of October and again in the first week of May for both 2014 and 2015 in all the populations. These months correspond to the beginning of the short rainy season of September/October and the long rainy season of April/May (Figure 3 and Table 1). 
TABLE 1: Phenological events of S. senegal within Lake Baringo woodland ecosystem for years 2014 and 2015.

\begin{tabular}{|c|c|c|c|c|c|c|c|c|}
\hline \multirow{2}{*}{ Population } & \multicolumn{4}{|c|}{2014} & \multicolumn{4}{|c|}{2015} \\
\hline & $\mathrm{LI}$ & LFI & PFL & PFR & LI & LFI & PFL & PFR \\
\hline Tangulbei & Apr. (Sep.) & Aug. (Feb.) & May (Oct.) & Jun. (Dec.) & May (Sep.) & Oct. (Feb.) & Jun. (Oct.) & Jul. (Dec.) \\
\hline Kampi Ya Samaki & Apr. (Sep.) & Aug. (Feb.) & May (Oct.) & Jun. (Dec.) & May (Sep.) & Oct. (Feb.) & Jun. (Oct.) & Jul. (Dec.) \\
\hline Kimalel & May (Sep.) & Oct. (Feb.) & Jun. (Oct.) & Jul. (Dec.) & Jun. (Sep.) & Nov. (Feb.) & Jul. (Oct.) & Aug. (Dec.) \\
\hline Lake Bogoria & May (Sep.) & Oct. (Feb.) & Jun. (Oct.) & Jul. (Dec.) & Jun. (Sep.) & Nov. (Feb.) & Jul. (Oct.) & Aug. (Dec.) \\
\hline
\end{tabular}

LI: leaf initiation; LFI: leaf fall initiation; PFL: peak flowering month; PFR: peak fruiting month.

TABLE 2: Correlation of S. senegal phenological events with climatic factors.

\begin{tabular}{lcccccccc}
\hline \multirow{2}{*}{ Environmental variables } & \multicolumn{2}{c}{ Leaf initiation } & \multicolumn{2}{c}{ Peak leaf fall } & \multicolumn{2}{c}{ Peak flowering } & \multicolumn{2}{c}{ Peak fruiting } \\
& Coeff. & $P$ value & Coeff. & $P$ value & Coeff. & $P$ value & Coeff. & $P$ value \\
\hline Maximum daily temperatures $\left({ }^{\circ} \mathrm{C}\right)$ & 0.226 & 0.106 & 0.414 & $0.001^{* *}$ & 0.140 & 0.076 & 0.212 & $0.044^{*}$ \\
Monthly total precipitation $(\mathrm{mm})$ & 0.358 & $0.031^{*}$ & -0.618 & $0.001^{* *}$ & 0.347 & $0.021^{*}$ & 0.492 & $0.001^{* *}$ \\
Mean relative humidity $(\%)$ & 0.116 & 0.091 & -0.172 & 0.082 & 0.121 & 0.218 & 0.018 & 0.912 \\
Mean soil moisture content $\left(\mathrm{m}^{3} / \mathrm{m}^{3}\right)$ & 0.488 & $0.001^{* *}$ & -0.322 & $0.001^{* *}$ & 0.278 & $0.037^{*}$ & 0.398 & $0.001^{* *}$ \\
\hline
\end{tabular}

${ }^{*}$ Significant at $P<0.05 ;{ }^{* *}$ significant at $P<0.01$.

The leaf initiation started one week earlier in Tangulbei and Kampi Ya Samaki than in Kimalel and Lake Bogoria populations in both seasons of the year 2014. In the year 2015, the event occurred at the same time for all the populations. The leafing duration (leaf initiation to complete leaf fall) lasted for about 18 weeks in both the years and seasons; however, Lake Bogoria population had a shorter leafing duration (17 weeks) than the other populations. The peak leaf fall (complete leaf loss) was observed to occur during the month of March/April and September in both 2014 and 2015 coinciding with the hot and dry seasons (Figure 3 and Table 1). The leaf fall was followed by fresh leaf emergence at the beginning of the subsequent rainy season of May (long rains) and October (short rains). Individual trees did not show any significant difference in leaf shedding patterns between the years.

3.3. Flowering Phenology. The species had two peak seasons in each year for flowering and fruit production which occurred during the short and long rainy seasons. The flowering period in all the populations begun at the onset of the rainy season just immediately after the leaf flush. This phase lasted for about 12 weeks with a one-month peak during the seasons. The flowering occurred between October and November during the short rains and May and June during the long rains. Flowering intensity was similar in both the years although the intensity was lower during the short than the long rainy season. In the year 2014, the first floral buds were observed at the beginning of May and mid-October for Lake Bogoria and Kimalel populations, while, for Kampi Ya Samaki and Tangulbei populations, the first flower buds were observed in the mid of May and mid-October. In the year 2015, the flower initiation occurred during mid of May and beginning of October for all the populations. The peak flowering times were observed during the last week of June to the first week of July in 2014 and mid of July to end of July in 2015. This was also observed from the end of October to the beginning of November in both years.
3.4. Fruiting Phenology. Fruit development proceeded during the rainy season with pod initiation starting in the last week of June and continuing till July while the maturation of pods started in mid-July and end of August for the years 2014 and 2015, respectively. These periods were not significantly different among the populations despite few day differences. The peak fruiting month, when majority of the individual tree had many fruits, was in June/July and December for the year 2014 and in July/August and December for the year 2015 (Table 1). The variation between the years was majorly due to variations in the onset of the seasons. For the two years combined, the peak fruiting month occurred in the months of July and December (Figure 3). Fruiting phenophase generally lasted for about three months (12 weeks) although it lasted for about 14 weeks during the long rains in both years.

3.5. Correlation with Climatic Variable. Spearman's rank correlation between the number of individual trees in different phenophases and the climatic variables is as shown in Table 2. There was positive correlation between leaf initiation and total monthly rainfall $(r=0.358, P<0.05)$ and mean soil moisture content $(r=0.488, P=0.001)$. Peak leaf fall was positively correlated to mean maximum temperature $(r=$ $0.414, P=0.001)$ and negatively related to mean monthly total precipitation $(r=-0.618, P=0.001)$. The correlation between numbers of individual trees flowering each month (all plots combined) and monthly rainfall showed that flowering occurred more often in wet than dry months and was positively correlated to mean total monthly rainfall ( $r=$ 0.347, $P<0.05)$. There was also a positive relationship between flowering and mean soil moisture content $(r=$ $0.278, P<0.05)$. The peak fruiting season was strongly positively correlated to mean total monthly precipitation $(r=$ $0.492, P=0.001)$ and mean monthly soil moisture content ( $r=398, P=0.001)$ but weakly positively correlated to mean daily maximum temperature $(r=0.212, P=0.044)$. 


\begin{tabular}{|l|c|c|c|c|c|c|c|c|c|c|c|c|}
\hline Population & $\mathrm{J}$ & $\mathrm{F}$ & $\mathrm{M}$ & $\mathrm{A}$ & $\mathrm{M}$ & $\mathrm{J}$ & $\mathrm{J}$ & $\mathrm{A}$ & $\mathrm{S}$ & $\mathrm{O}$ & $\mathrm{N}$ & $\mathrm{D}$ \\
\hline Tangulbei & $\bullet$ & $\bullet$ & 0 & $\bullet$ & $\bullet$ & $\bullet$ & $\bullet$ & 0 & $\bullet$ & $\bullet$ & $\bullet$ \\
\hline Kampi Ya Samaki & $\bullet$ & $\bullet$ & $\circ$ & $\bullet$ & $\bullet$ & $\bullet$ & $\bullet$ & 0 & $\bullet$ & $\bullet$ & $\bullet$ & $\bullet$ \\
\hline Kimalel & $\bullet$ & $\bullet$ & 0 & $\bullet$ & $\bullet$ & $\bullet$ & $\bullet$ & 0 & $\bullet$ & $\bullet$ & $\bullet$ \\
\hline Lake Bogoria & $\bullet$ & $\bullet$ & 0 & $\bullet$ & $\bullet$ & $\bullet$ & $\bullet$ & 0 & $\bullet$ & $\bullet$ & $\bullet$ \\
\hline
\end{tabular}
Leafing Peak flowering
- Complete leaf fall
Flowering

(a) Monthly phenological events

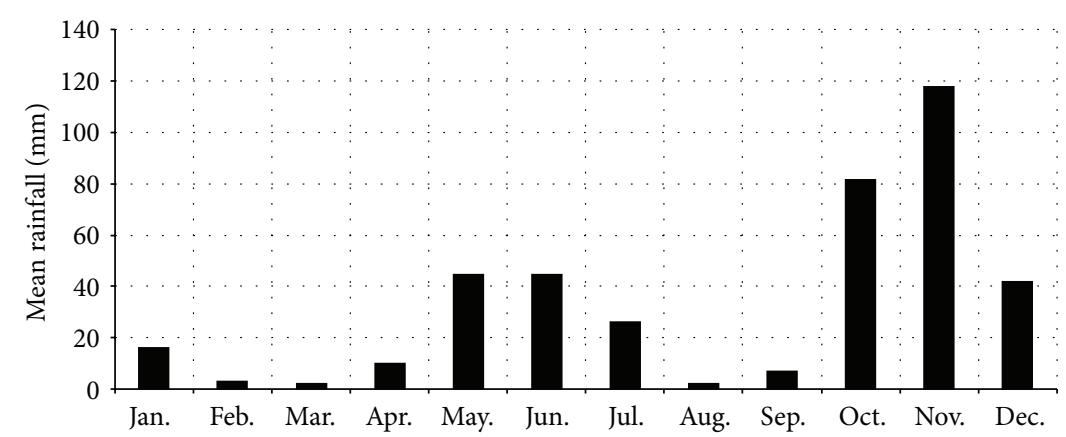

(b) Monthly rainfall data

Figure 3: (a) Monthly leafing, flowering, and fruiting events of S. senegal and (b) mean monthly rainfall amounts in Lake Baringo woodland ecosystem.

TABLE 3: Synchrony indices for phenological events of S. senegal within Lake Baringo woodland ecosystem.

\begin{tabular}{lccc}
\hline Population & \multicolumn{3}{c}{$\begin{array}{c}\text { Synchrony index } \\
\text { Flowering }\end{array}$} \\
\hline Tangulbei & 0.78 & 0.85 & 0.74 \\
Kampi Ya Samaki & 0.81 & 0.74 & 0.88 \\
Kimalel & 0.91 & 0.80 & 0.79 \\
Lake Bogoria & 0.85 & 0.78 & 0.82 \\
Overall & 0.87 & 0.75 & 0.85 \\
\hline
\end{tabular}

The values are means of the two annual cycles.

3.6. Synchrony of Phenological Events. In determining the synchrony of phenological events of the individuals within and among populations, the results are as shown in Table 3. The leafing stage was synchronous within and among the populations with many individuals initiating leafing at the end of the dry season and the beginning of rainy season and initiating leaf fall at the beginning of the dry season for both of the years. The overall interpopulation synchrony ratio for leaf development was 0.87 (Table 3). The overall interpopulation synchrony ratio for flowering and fruiting phenology was 0.75 and 0.85 , respectively (Table 3 ). Higher synchrony ratio indicates greater coincidence of the phase among individuals or sites.

3.7. Floral Morphology. The floral characteristics were assessed during the peak flowering seasons and the results are as shown in Table 4. The number of flowers per inflorescence ranged between 89 and 134 flowers with a grand mean of
92.7. Significant difference was recorded among populations $\left(F_{3,1247}=23.53 ; P<0.05\right)$. The inflorescence length ranged from 5.9 to 6.2 with a grand mean of 6.1; however, no significant difference was observed among the populations. There were also significant differences in flower length $\left(F_{3,1827}=20.66 ; P<0.05\right)$, stigma diameter $\left(F_{3,1827}=9.19\right.$; $P<0.05)$, style length $\left(F_{3,1827}=3.96 ; P<0.05\right)$, and number of ovules per ovary $\left(F_{3,1208}=21.28 ; P<0.05\right)$ among the populations. No significant difference was observed among the populations on inflorescence length (Table 4). High mean number of flowers per inflorescence was found in Kimalel population with the least number observed in Kampi Ya Samaki population. Generally, considering both years and all the seasons, Kimalel population registered the largest values in flower length, stigma diameter, and the mean number of ovules per ovary. The longest style length was observed in Kampi Ya Samaki population (Table 4).

3.8. Pollen Quality. There was no significant difference in polyad diameter among the populations. Tangulbei population showed larger polyad diameter compared to the other populations (Table 5). Pollen germination was as shown in Figure 4. Significant differences in pollen germination percentage were found among the populations $\left(F_{3,472}=4.73\right.$; $P<0.05)$ with lower germination rates reported for Lake Bogoria and Kimalel populations. Significant difference was also observed for stigma diameter among the populations $\left(F_{3,1827}=9.19 ; P<0.05\right)$ with Tangulbei population showing large stigma diameter size compared to the other populations. In all the populations, stigma diameter was larger than the polyad diameter. 
TABLE 4: Floral characteristics of $S$. senegal within Lake Baringo woodland ecosystem.

\begin{tabular}{lcccccc}
\hline Population & FS & SL & FL & SD & STL & OPV \\
\hline Kampi Ya Samaki & $88.99^{\mathrm{a}}$ & $6.12^{\mathrm{a}}$ & $7.16^{\mathrm{a}}$ & $0.24^{\mathrm{a}}$ & $6.61^{\mathrm{b}}$ & $4.49^{\mathrm{a}}$ \\
Lake Bogoria & $87.68^{\mathrm{a}}$ & $5.95^{\mathrm{a}}$ & $7.21^{\mathrm{ab}}$ & $0.25^{\mathrm{a}}$ & $6.63^{\mathrm{a}}$ & $4.43^{\mathrm{a}}$ \\
Tangulbei & $89.28^{\mathrm{a}}$ & $6.21^{\mathrm{a}}$ & $7.33^{\mathrm{b}}$ & $0.24^{\mathrm{a}}$ & $6.63^{\mathrm{ab}}$ & $4.76^{\mathrm{b}}$ \\
Kimalel & $103.21^{\mathrm{b}}$ & $6.25^{\mathrm{a}}$ & $7.52^{\mathrm{c}}$ & $0.26^{\mathrm{b}}$ & $6.84^{\mathrm{ab}}$ & $5.05^{\mathrm{c}}$ \\
Difference between years & ns & ns & ns & ns & ns & ns \\
\hline
\end{tabular}

FS: number of flowers per inflorescence; SL: inflorescence length $(\mathrm{cm}) ; \mathrm{FL}$ : flower length $(\mathrm{mm})$; SD: stigma diameter $(\mathrm{mm})$; STL: style length $(\mathrm{mm})$; OPV: number of ovules per ovary; ns: not significant; data followed by the same letter are not significantly different at 95\% using Fisher's LSD test.

TABLE 5: Mean pollen germination percentage for the four populations of S. senegal within Lake Baringo woodland ecosystem.

\begin{tabular}{lccc}
\hline Population & PD $(\mathrm{mm})$ & SD $(\mathrm{mm})$ & PG $(\%)$ \\
\hline Kimalel & $0.1651^{\mathrm{a}}$ & $0.24^{\mathrm{a}}$ & $55.80^{\mathrm{ab}}$ \\
Kampi Ya Samaki & $0.1725^{\mathrm{a}}$ & $0.25^{\mathrm{a}}$ & $63.32^{\mathrm{b}}$ \\
Lake Bogoria & $0.1748^{\mathrm{a}}$ & $0.24^{\mathrm{a}}$ & $52.33^{\mathrm{a}}$ \\
Tangulbei & $0.1750^{\mathrm{a}}$ & $0.26^{\mathrm{b}}$ & $60.60^{\mathrm{ab}}$ \\
\hline
\end{tabular}

PD: polyad diameter; SD: stigma diameter; PG: pollen germination; data followed by the same letter are not significantly different at 95\% using LSD test.

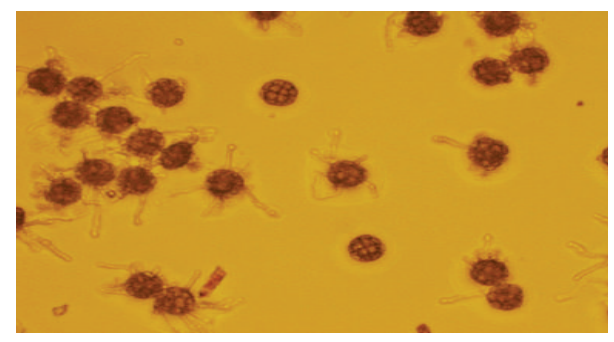

FIGURE 4: Examples of germinated and ungerminated pollen grains of $S$. senegal.

3.9. Pods and Seed Yield. In both years, the pods measured between 3.4 and $16.9 \mathrm{~cm}$ long and 1.1 and $3.2 \mathrm{~cm}$ wide with the means per population as shown in Table 6. Both the pod length $\left(F_{3,116}=17.53 ; P<0.05\right)$ and pod width $\left(F_{3,116}=39.39 ; P<0.05\right)$ were significantly different among the populations. Over all the period, Kampi Ya Samaki and Kimalel populations showed larger pod measurements than Tangulbei and Lake Bogoria populations. The number of seeds per pod varied between 2 and 6 per population but did not differ significantly among populations. However, most of the trees from Kimalel population recorded more number of seeds per pod compared to the other populations. The average percentage of developed seeds per pod per tree was similar in all the populations ranging from 65 to $95 \%$. There were no significant differences between years for either trait. Significant difference on seed length $\left(F_{3,116}=18.97 ; P<\right.$ $0.05)$, width $\left(F_{3,116}=28.95 ; P<0.05\right)$, and weight $\left(F_{3,116}=\right.$ $7.10 ; P<0.05)$ was found among the populations with Lake Bogoria population recording lower values for both the traits
TABLE 6: Pod and seed characteristics of S. senegal within Lake Baringo woodland ecosystem.

\begin{tabular}{lccccc}
\hline Population & PL & PW & SPP & SW & FF (\%) \\
\hline Tangulbei & $4.6^{\mathrm{ab}}$ & $2.2^{\mathrm{b}}$ & $4^{\mathrm{a}}$ & $66^{\mathrm{b}}$ & $72^{\mathrm{a}}$ \\
Kampi Ya Samaki & $5.2^{\mathrm{bc}}$ & $1.8^{\mathrm{a}}$ & $5^{\mathrm{a}}$ & $71^{\mathrm{b}}$ & $81^{\mathrm{a}}$ \\
Kimalel & $5.8^{\mathrm{c}}$ & $2.6^{\mathrm{c}}$ & $5^{\mathrm{a}}$ & $64^{\mathrm{ab}}$ & $88^{\mathrm{a}}$ \\
Lake Bogoria & $3.9^{\mathrm{a}}$ & $1.8^{\mathrm{a}}$ & $3^{\mathrm{a}}$ & $58^{\mathrm{a}}$ & $93^{\mathrm{a}}$ \\
Difference among populations & $*$ & $*$ & $\mathrm{~ns}$ & $* *$ & $\mathrm{~ns}$ \\
\hline
\end{tabular}

${ }^{* *}$ Significant at $P<0.01 ;{ }^{*}$ significant at $P<0.05$; ns: nonsignificant; PL: pod length; PW: pod width; SPP: number of seeds per pod; SW: weight of 1000 seeds; FF: fully formed seeds; data followed by the same letter are not significantly different at 95\% using Fisher's LSD test.

than the other populations. The average seed weight ranged between 42 and $76 \mathrm{~g} / 1000$ seeds and varied significantly among seasons with the long rainy seasons reporting heavier seeds per 1000 seeds than the short rainy seasons $\left(F_{1,119}=\right.$ 12.9; $P<0.05)$. The seed weights did not differ significantly between the years.

\section{Discussion}

4.1. Leafing Phenology. Phenological investigations show that, in most tropical forests, rainfall is one of the most likely environmental changes controlling the periodicity of tree growth and flowering [2]. It is also generally believed that occurrence of rainfall after a period of drought or long dry spell usually initiates plant growth mainly in the dry forest ecosystems such as Lake Baringo woodland [26]. The present study has shown that $S$. senegal usually sheds most of its leaves during the dry season when the soil moisture content is very low and the atmospheric temperatures are high. As a defense mechanism to tolerate drought or the dry conditions, the species drop leaves and regain them during the rainy seasons [12]. With the start of the rains, the tree produces leaf buds that initiate the leafing phenophase. This phenomenon has been reported for many dry forest species [25]. Generally, the onset of rains improves soil moisture content that triggers the tree to begin growth. Once the first new leaves of the season have expanded, the production of leaf buds and young leaves continues constantly until the whole crown is covered with leaves. During this period, there is no distinguishable transition from old to new leaves. This may take between 16 and 18 weeks depending on the length of the rainy season. Complete leaf cover is achieved in the mid of the rainy season and correlated with high water availability both in terms of both rainfall amounts and soil water content (Table 2). This type of development of leaves is more closely connected to changing conditions in water availability than was observed for flowering or fruit production [6]. A high percentage of mature leaves are retained almost throughout the rainy season. The leaf formation and duration was observed to be synchronous within and among the four populations (Table 3). This may be due to the similarity of the dynamics of environmental conditions of the populations. It was noted during the present study that most of the environmental variables occur, generally, at the same time hence triggering 
the phenophases of the species in the four populations almost simultaneously. The leafing event was not different between the years. However, some small variations were found in terms of duration, which could be explained by variation in the durations of the environmental condition. For example the leafless period during the year 2014 was one week longer than the year 2015; however, the sequences of events were similar. Similar results were also reported for Lagerstroemia speciosa by Khanduri [2].

\subsection{Flowering Phenology. Senegalia senegal flowered during} the rainy season which was similar to many other Acacia species within the woodland and other tropical species so far studied [26]. During the present study, S. senegal is reported to initiate flowering few weeks after the beginning of the rains when over $65 \%$ of the crown has been covered by new leaves. The peak flowering was actually realized at the peak rainy months which signifies the importance of precipitation to $S$. senegal during the flowering season. Most studies have reported that, for species that flowers during the rainy season, the onset of heavy rains usually act as a cue that triggers flowering ([26] and the references therein). Actually, during the present study, the peak flowering month was positively correlated with the peak rainy months and soil moisture content. Similar results were reported for $S$. senegal by Tandon et al. [27] in India indicating that the species prefers flowering during the rainy seasons. It has also been reported that $S$. senegal in some places may respond by flowering even with unseasonal rains [11]. Principally, most tree species found in dry forest ecosystems normally utilizes the short favorable rainy seasons for leaf development and to accumulate sufficient photosynthate and initiate reproduction before the soil moisture starts to fall in the subsequent drier season [26].

Few studies have examined the possible functional significance of an interrelationship between leafing and flowering/fruiting phenophases in tropical trees; however this occurrence may be attributed to the need for substantial amount of resources to sustain reproduction [28]. Senegalia senegal, therefore, just like the other species with similar phenological behavior, requires to undertake photosynthesis to sustain it during the reproductive phase. As described by Sing and Kushwaha [26], flower production and maintenance require considerable expense of energy to form nonphotosynthetic tissues and nectar. This phenomenon therefore requires the availability of foliage for photosynthesis to sustain the physiological activities during flowering. Some amounts of soil moisture will be required during this process; hence the rainy season is the best time for the species to flower. The peak flowering month was not significantly correlated with the relative humidity; however, the phenophase occurred during high relative humidity ranging between 48 and $62 \%$. This finding corroborates the results reported by Stone et al. [29] that relative humidity of between 50 and 60\% is correlated with peak pollen availability. Such high relative humidity may be necessary for $S$. senegal to enhance pollen transfer and fertilization.

The present study revealed significant flowering synchrony among populations and individuals within the populations. The synchrony illustrates the plasticity of the individual trees that may contribute, to a large extent, to population maintenance and connectivity in the woodland. The synchrony may benefit the species by providing an opportunity for pollen transfer within and among the populations hence ensuring high genetic diversity and preventing differentiation. Such genetic impact has been reported for the species by harboring higher genetic diversity with limited population differentiation [16]. The flowering event was similar in both the years in terms of timing and proportion of individual trees with flowers within the months. The two rainy seasons were also not significantly different in flowering intensity. This may mean that the reproductively mature trees flower similarly when triggered by the environmental cues.

4.3. Fruiting Phenology. The fruiting phase of the species lasted for about three months in both seasons and years. This occurred during the peak rainy season until the seeds were mature and ready for dispersals and probably germinations. This timing of fruiting during the rainy season is to allow for fruit growth and maturation since this stage requires a lot of photosynthates [9]. As the rains subside and the dry season creeps in, almost all the fruits were mature and ripe in readiness for dispersal and even germination. Fruit maturation and presence of suitable conditions for dispersal are closely synchronized in tropical dry forest species because of the pronounced differences of biotic and abiotic conditions between dry and rainy seasons [30].

Senegalia senegal seeds are mainly dispersed by wind and ungulates whose activities are more predominant during the dry seasons. The timing of the season is therefore very important to the species evolution [13]. In most of the dry forest ecosystems, strong winds are common during the dry seasons providing an opportunity for dispersals to wind dispersed seeds like those of $S$. senegal [25]. Furthermore, it is during this same period that the $S$. senegal pods are an important source of fodder for livestock and other herbivores who are also potential seed dispersers of the species [12]. In this study, the greater percentage of individual trees with mature pods (brown pods) was observed towards the end of the rainy season with large number of trees with dry pods occurring during the dry season. The fruiting phenophase was also found to be synchronous within and among populations just as leafing and flowering events. However, the fruits stayed longer in both Kimalel and Kampi ya Samaki populations than in Tangulbei and Lake Bogoria populations. These variations may have been brought about by variations in soil characteristics. The soils found in Kimalel and Kampi Ya Samaki populations are loamy and therefore able to retain moisture for a longer period than the soils in Tangulbei and Lake Bogoria which are majorly sandy and rocky [17]. The soil moisture may have sustained the fruit in green form for a longer period.

4.4. Floral Morphology and Pollen Quality. In order to understand $S$. senegal reproductive potential, after every flowering season, the floral morphology and pollen viability were studied. The flowers of S. senegal are generally creamy white and typically arranged along the inflorescence opening along the axis starting from the base. This observation was similar 
to the characteristics reported by Fagg and Allison [12] and Chiveu et al. [31]. The floral morphology differed significantly among the populations in all the variables except inflorescence length. The variables however did not differ significantly between the years and seasons. In addition, analysis of the traits within the populations showed no significant differences. In most of the traits, Kimalel population showed larger values compared to the other populations. For instance, the length of flower inflorescence in Kimalel was the longest and it is from the same population that the largest number of flowers per inflorescence was observed. This indicates that the length of the inflorescence may be influencing the number of flowers per inflorescence. This is consistent with research results reported for some Australian Acacias with similar floral architecture [23]. Despite Kimalel having the longest inflorescence length, there was no significant difference in the trait among the populations. The longer inflorescence length and large number of flowers per inflorescence may also be linked to the climatic variability within the ecosystem. This is basically because Kimalel population within the two years recorded the highest amounts of monthly rainfall and soil moisture content during the flowering period compared to other populations. Kimalel population also recorded the largest stigma diameter and style length compared to the other populations. The development and growth of these organs may be influenced by the flower size whereby the longer the flower length, the longer the style length and the larger the stigma diameter. Favorable climatic condition may also promote larger sizes of these organs [23].

Generally, pollen quality is one of the very important factors in successful plant reproduction and more so to Acacia species whose seed production usually occurs after only a single pollination activity [23]. Over $50 \%$ pollen germination was reported in all the populations although there was significant difference among the populations. Lake Bogoria population showed lower pollen germination percentage during the year 2014 short rains compared to the other population. This difference may have been brought about by the fluctuation in environmental conditions required for pollen maturity [32]. During this period of time, Lake Bogoria population experienced sporadic rainfall pattern compared to the other populations. This occurrence may have affected the floral development and maturity by delaying its formation. The flowers might have been caught up by harsh environmental conditions which in the long run affected the pollen quality. Such incidences have been reported by Tandon et al. [27]. However, poor pollen germination may also have been contributed by ageing of the flowers. Flowers collected late after anthesis normally result in poor germination. Probably some of the flowers collected from Lake Bogoria population were old and this might have significantly contributed to the poor germination. Similar results have also been reported for $A$. mangium and A. auriculiformis with low germination attributed to both environmental factors and ageing of the flowers [23].

The pollen quality did not differ significantly between the seasons or years. This is contrary to most studies that have shown significant variation between seasons and years ([2] and references therein). However, lack of significant differences within the woodland may be explained by the relatively similar weather patterns experienced during the study period. In the long run, the pollen quality did not have effect on the number of pods set per flower inflorescence pollinated and did not affect either the quality or the number of seeds realized per pod. Furthermore, the pollen viability reported in all the populations was sufficient to produce open pollinated seeds.

4.5. Pods and Seed Production. Senegalia senegal produced pods with variable dimensions. The pod length ranged from 3.4 to $8.2 \mathrm{~cm}$ and the width varied from 1.1 to $3.2 \mathrm{~cm}$. These values were significantly different among populations, although no differences were found between the years or seasons (long and short rainy seasons). The differences may be attributed to soil factors and environmental variables. Kampi Ya Samaki and Kimalel populations that showed larger pod dimension than the other populations also recorded higher amount of rainfall than the other populations during this study. In this case, rainfall amount could be a factor in pod sizes. Nghiem et al. [23] in their study of fruit morphology of A. mangium and A. auriculiformis also reported significant variation in these traits and attributed it to varying environmental conditions. However, genetic variability of the individual trees concerned may also play a significant role. Similar variations in pod characteristics were also reported on S. senegal by Chiveu et al. [31] and these were attributed to both genetic differences and heterogeneity of environmental conditions among the sites.

Significant variation among populations was also realized on the weight of 1000 seeds. Heavy seeds were found in Kampi Ya Samaki population but no significant difference was realized within populations. The seed weights also did not differ between the seasons and years similar to percentages of fully formed seed. In many studies, seed weight has been viewed to mainly represent genetic differences which may be brought about by adaptation strategy of species. In most cases, some species tend to develop smaller and lighter seeds in drier and harsh environmental conditions compared to those in favorable environments. Similar results were also reported for $S$. senegal from different populations with variable environmental conditions [31]. The smaller and lighter seeds in drier areas reported in this study are contrary to the findings reported by Chaisurisri et al. [33] who correlated seed size to environmental dryness and found out that the seed size increases with dryness. They believed that the drier condition forces the trees to store more food in the seed for use during germination and regeneration. However such adaptation may vary accordingly with species.

\section{Conclusions}

Despite the fragmentation of $S$. senegal population within Lake Baringo woodland, the species has reported higher degree of phenological synchrony within and among the populations. It is also noted that all the phenophases were environmentally triggered and therefore the synchrony reported here may confidently be attributed to almost similar environmental condition within the woodland. The synchrony 
may also be an evolutionary strategy of the species to sustain reproduction. Furthermore, the seasonal leafing, flowering time, and fruiting duration, with linkages to leafing and leafless durations, observed in the species suggest the reproductive and survival strategies evolved by the species to adapt to the harsh environment. Although there were significant differences in some aspects of the morphology of flower length, stigma diameter, style length, and ovules per ovary among populations, these differences were only small and did not appear to affect crossing among individuals and populations. It is therefore worth concluding that there were no barriers in phenophase or flower structure to prevent interpopulation reproduction which would enhance genetic diversity and connectivity among populations.

\section{Competing Interests}

The authors declare that there are no competing interests regarding the publication of this paper.

\section{Acknowledgments}

The study was funded by Kenya Forestry Research Institute (KEFRI) and International Foundation of Science (IFS) Research Grant no. D5452-1 to Stephen F. Omondi as part of his Ph.D. thesis. The authors are grateful to KEFRI Biotechnology Laboratory and Baringo Sub-Regional Centre of the Rift Valley Eco-Regional Research Programme for helping during field sampling and data collection.

\section{References}

[1] E. E. Cleland, I. Chuine, A. Menzel, H. A. Mooney, and M. D. Schwartz, "Shifting plant phenology in response to global change," Trends in Ecology and Evolution, vol. 22, no. 7, pp. 357365, 2007.

[2] V. P. Khanduri, "Annual variation in floral phenology and pollen production in Lagerstroemia speciosa: an entomophilous tropical tree," Songklanakarin Journal of Science and Technology, vol. 36, no. 4, pp. 389-396, 2014.

[3] X. Zhang, M. A. Friedl, and C. B. Schaaf, "Global vegetation phenology from Moderate Resolution Imaging Spectroradiometer (MODIS): evaluation of global patterns and comparison with in situ measurements," Journal of Geophysical Research, vol. 111, no. 4, p. 4017, 2006.

[4] N. C. Duke, "Phenological trends with latitude in the mangrove tree Avicennia marina," Journal of Ecology, vol. 78, no. 1, pp. 113133, 1990.

[5] R. Milla, P. Castro-Díez, M. Maestro-Martínez, and G. Montserrat-Martí, "Costs of reproduction as related to the timing of phenological phases in the dioecious shrub Pistacia lentiscus L.," Plant Biology, vol. 8, no. 1, pp. 103-111, 2006.

[6] J. B. L. Okullo, J. B. Hall, and J. Obua, "Leafing, flowering and fruiting of Vitellaria paradoxa subsp. nilotica in savanna parklands in Uganda," Agroforestry Systems, vol. 60, no. 1, pp. 77-91, 2004.

[7] C. K. Augspurger, "Phenology, flowering synchrony, and fruit set of six neotropical shrubs," Biotropica, vol. 15, no. 4, pp. 257267, 1983.
[8] M. S. Abu-Asab, P. M. Peterson, S. G. Shetler, and S. S. Orli, "Earlier plant flowering in spring as a response to global warming in the Washington, DC, area," Biodiversity and Conservation, vol. 10, no. 4, pp. 597-612, 2001.

[9] D. Lieberman, "Seasonality and phenology in a dry tropical forest in Ghana," Journal of Ecology, vol. 70, no. 3, pp. 791-806, 1982.

[10] P. A. Huxley, "Phenology of tropical woody perennials and seasonal crop plants with reference to their management in agroforestry systems," in Plant Research and Agroforestry, P. A. Huxley, Ed., pp. 503-525, ICRAF, Nairobi, Kenya, 1983.

[11] K. Tybirk, "Pollination, breeding system and seed abortion in some African Acacias," Botanical Journal of the Linnean Society, vol. 112, no. 2, pp. 107-137, 1993.

[12] C. W. Fagg and G. E. Allison, Acacia Senegal and Gum Arabic Trade, Tropical Forestry Papers no. 42, Oxford Forestry Institute, 2004.

[13] E. O. Obunga, A Study of Genetic Systems of Four African Species of Acacia, School of Biological Science, University of Sussex, 1995.

[14] L. M. Kiage, K. B. Liu, N. D. Walker, N. Lam, and O. K. Huh, "Recent land-cover/use change associated with land degradation in the Lake Baringo catchment, Kenya, East Africa: evidence from Landsat TM and ETM+," International Journal of Remote Sensing, vol. 28, no. 19, pp. 4285-4309, 2007.

[15] J. K. Lelon, Uptake of Micronutrients by Acacia Senegal Varieties and Its Possible Effects on Gum Arabic Quality, The University of Nairobi, Nairobi, Kenya, 2008.

[16] S. F. Omondi, E. Kireger, O. G. Dangasuk et al., "Genetic diversity and population structure of Acacia senegal (L) Willd. in Kenya," Tropical Plant Biology, vol. 3, no. 1, pp. 59-70, 2010.

[17] W. G. Sombroek, H. M. H. Braun, and B. J. A. Van der Pouw, Exploratory Soil Map and Agro-limatic Zone Map of Kenya. Scale 1:1 000 000, vol. 1:1 000 of Exploratory Soil Survey Report no. E1, Kenya Soil Survey, 1982.

[18] E. A. Y. Raddad, A. A. Salih, M. A. E. Fadl, V. Kaarakka, and O. Luukkanen, "Symbiotic nitrogen fixation in eight Acacia senegal provenances in dryland clays of the Blue Nile Sudan estimated by the $15 \mathrm{~N}$ natural abundance method," Plant and Soil, vol. 275, no. 1-2, pp. 261-269, 2005.

[19] L. R. Arce and H. Banks, "A preliminary survey of pollen and other morphological characters in neotropical Acacia subgenus Aculeiferum (Leguminosae: Mimosoideae)," Botanical Journal of the Linnean Society, vol. 135, no. 3, pp. 263-270, 2001.

[20] B. N. Chikamai and J. A. Odera, Commercial Plant Gums and Resins in Kenya, Executive Printers, Nairobi, Kenya, 2002.

[21] P. M. Maundu, G. W. Ngugi, and H. C. Kasuye, Traditional Food Plants of Kenya, Nairobi, Kenya, 1999.

[22] C. J. Chiveu, O. G. Dangasuk, M. E. Omunyin, and F. N. Wachira, "Genetic diversity in Kenyan populations of Acacia senegal (L) willd revealed by combined RAPD and ISSR markers," African Journal of Biotechnology, vol. 7, no. 14, pp. 23332340, 2008.

[23] C. Q. Nghiem, C. E. Harwood, J. L. Harbard, A. R. Griffin, T. H. Ha, and A. Koutoulis, "Floral phenology and morphology of colchicine-induced tetraploid Acacia mangium compared with diploid A. Mangium and A. Auriculiformis: implications for interploidy pollination," Australian Journal of Botany, vol. 59, no. 6, pp. 582-592, 2011.

[24] F. W. Martin, "Staining and observing pollen tubes in the style by means of fluorescence," Stain Technology, vol. 34, no. 3, pp. 125-128, 1959. 
[25] J.-L. Devineau, "Seasonal rhythms and phenological plasticity of savanna woody species in a fallow farming system (southwest Burkina Faso)," Journal of Tropical Ecology, vol. 15, no. 4, pp. 497-513, 1999.

[26] K. P. Singh and C. P. Kushwaha, "Diversity of flowering and fruiting phenology of trees in a tropical deciduous forest in India," Annals of Botany, vol. 97, no. 2, pp. 265-276, 2006.

[27] R. Tandon, K. R. Shivanna, and H. Y. Mohan Ram, "Pollination biology and breeding system of Acacia senegal," Botanical Journal of the Linnean Society, vol. 135, no. 3, pp. 251-262, 2001.

[28] C. P. Van Schaik, J. W. Terborgh, and S. J. Wright, “The phenology of tropical forests: adaptive significance and consequences for primary consumers," Annual Review of Ecology and Systematics, vol. 24, no. 1, pp. 353-377, 1993.

[29] G. N. Stone, P. Willmer, and J. A. Rowe, "Partitioning of pollinators during flowering in an African Acacia community," Ecology, vol. 79, no. 8, pp. 2808-2827, 1998.

[30] L. M. S. Griz and I. C. S. Machado, "Fruiting phenology and seed dispersal syndromes in caatinga, a tropical dry forest in the northeast of Brazil," Journal of Tropical Ecology, vol. 17, no. 2, pp. 303-321, 2001.

[31] C. J. Chiveu, O. G. Dangasuk, M. E. Omunyin, and F. N. Wachira, "Quantitative variation among Kenyan populations of Acacia senegal (L.) Willd. for gum production, seed and growth traits," New Forests, vol. 38, no. 1, pp. 1-14, 2009.

[32] J. Kenrick, Some Aspects of the Reproductive Biology of Acacia, University of Melbourne, Parkville, Australia, 1994.

[33] K. Chaisurisri, D. G. W. Edwards, and Y. A. El-Kassaby, "Genetic control of seed size and germination in Stika spruce," Silvae Genetica, vol. 41, no. 6, pp. 348-355, 1992. 

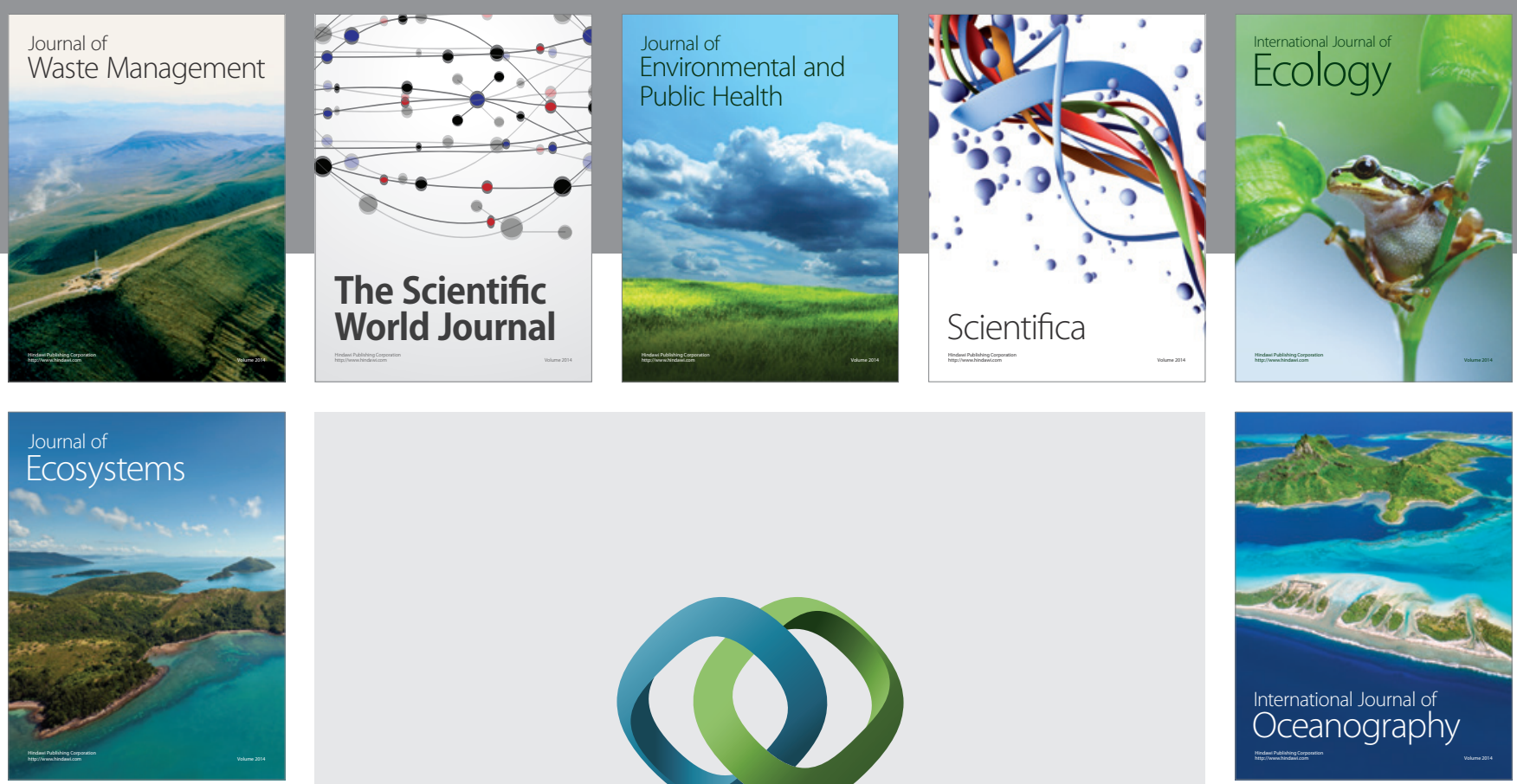

The Scientific World Journal
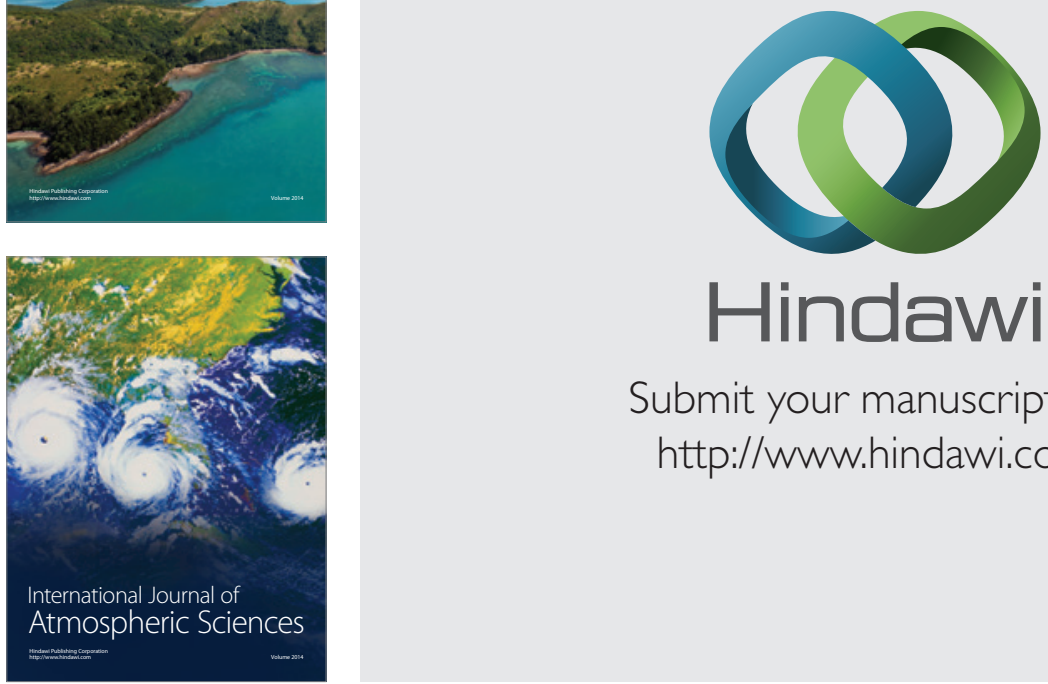

\section{Hindawi}

Submit your manuscripts at

http://www.hindawi.com
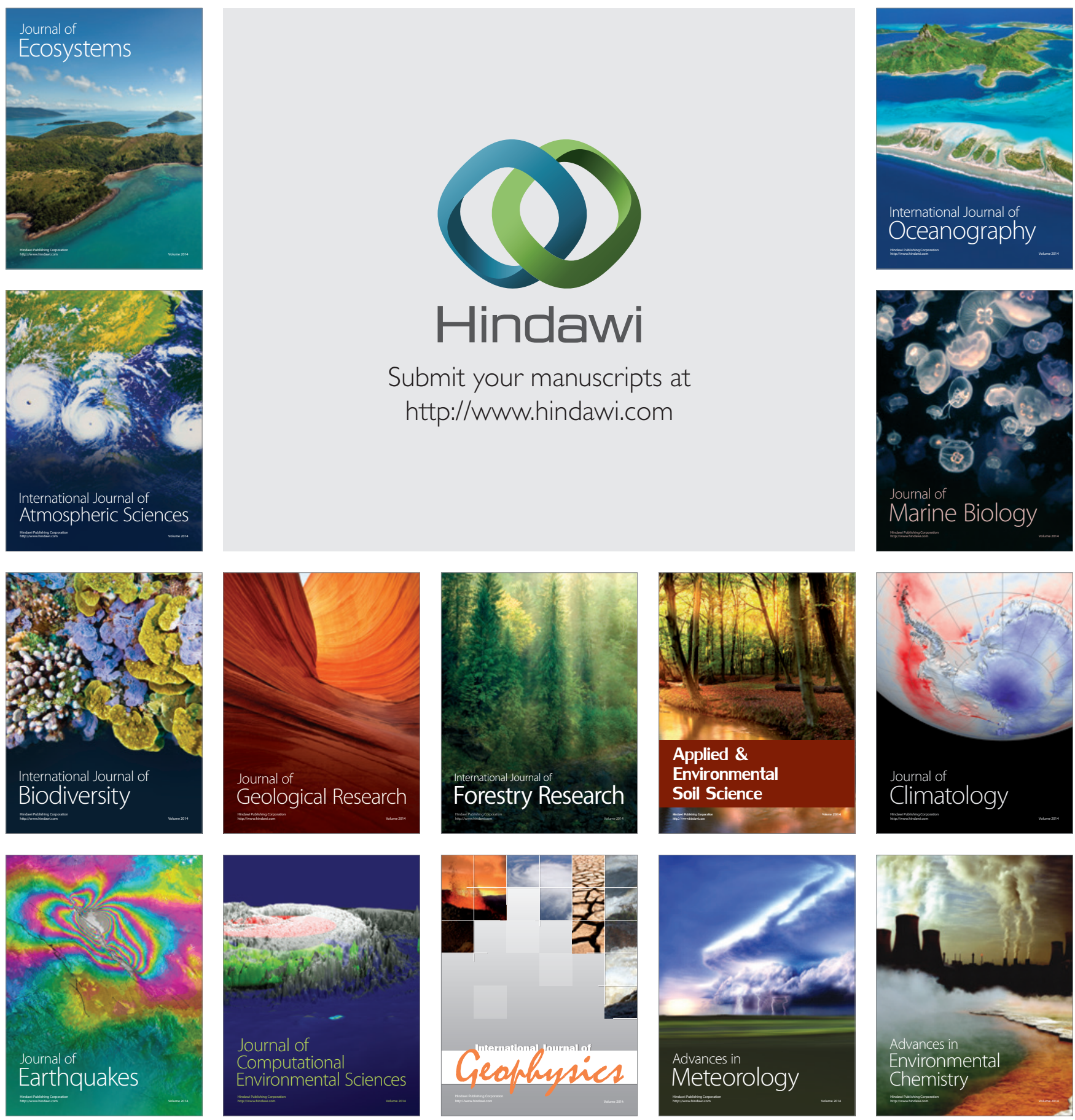